was given to the treatment of singularities, and a general debate ensued on the kind of problems that numerical analysts ought to be cxamining.

The final session on the morning of September 29 was devoted largely to what must be the most challenging problem to fluid dynamicists, namely, the solution of the full Navier-Stokes equations. In the first lecture, Dr. S. C. R. Dennis of the University of Sheffield surveyed the progress to date in the field of steady flow, and discussed in considerable detail the difficulties that arise in tackling the classical external problem of two-dimensional flow past a circular cylinder. In particular, ho considered suggestions that might overcome the major difficulty of the flow in the wake, which is especially troublesome at higher Reynolds numbers.

In the next lecture, on "Unsteady Flow", Dr. J. E. Fromm of the Los Alamos Scientific Laboratory demonstrated the feasibility of using a large digital computer to simulate the complex asymmetric fluid motions which really do occur in practical flow régimes, where the steady flow is unstable. He first gave a description of a finite difference technique for obtaining solutions of the twodimensional unsteady Navier-Stokes equations which had been developed with due regard for stability and conservation propertics. He then showed a series of impressive ciné films of the computer output for several flow problems. In order to make best use of the finite computer storage, only restricted flow fields were considered, namely, those between parallel plates. In the first problem the plates were moved so as to accelerate the fluid past a rectangular body; in the second the same configuration was considered, but the uncoupled temperature equation was solved as well, so as to simulate forced heat convcction from the body. In the third problem, the Benard problem of thermal convection between fixed plates was considered; here, of course, the coupling between the temperature and momentum equations had to be taken into account. The filmed computer output showed the development in time of the streak-lino patterns, the general features of which resembled the corresponding patterns produced in experiments to a remarkable degree. Shown also were the changing vorticity line patterns (or for the convection problems isotherm patterns). It should bo noted that if the data given were exactly symmetric, the symmetry was preserved in the solutions. The asymmetry had to be stimulated by introducing small perturbations; these were damped out for small Reynolds numbers, but amplified into typical eddying motions for larger Roynolds numbers. In the discussion group $A$ that followed (chaired by Prof. I. Proudman, University of Essex), it was pointed out that external flow problems were substantially more difficult to deal with numerically than internal ones, and Dr. Dennis suggested that a combination with analytical treatment of the far ficld might be the answer; howover, it would be very interesting to see Dr. Fromm's method applied directly to external flow problems. Another restriction that had been imposed because of limited storage capacity was a periodic boundary condition in the general flow direction; it would be of considerable interest to remove this so that any ultimate quasisteady patterns for large times could be studied.
The other two discussion groups on this last morning were: $B$, "Internal Aerodynamics" (chairman, Prof. J. H. Horlock, University of Liverpool) and $C$, "Turbulent Boundary-layers" (chairman, Prof. A. D. Young, Queen Mary College). Mr. R. Hetherington of Rolls-Royce, Ltd., gave an introductory talk in discussion group $B$, in which he discussed the two main two-dimensional problems that were used to model the essentially threedimensional process of flow through the complex of rotating and stationary blades that comprise a turbomachine. These are concerned mainly with eurved axial flow and cascade flow, respectively. Presently available methods wore briefly described and the extent to which computers were being used was surveyed. Although new methods were clearly needed to deal with the non-linear compressible and viscous effects, it was concluded that much could still be gained by developing existing methods with the aid of the modern computer.

The subject of turbulent boundary layers is, of course, of the utmost practical importance, but, up to the present, methods for calculating them have been developed on a purely empirical basis. Discussion group $C$ did, however, indicate that some substantial progress towards removing the empiricism from the direct relationship between shear stress and mean velocity profile to a less critical level is at last being made through analysis of the turbulent energy equation. This method leads (in two-dimensional flow) to a third-order hyperbolic system of partial differential equations, for which a characteristics method has been devised for solution on the computer. The computer can also be used to develop the traditional approach by exploring quickly and accurately the consequences of the various empirical assumptions regarding the relationship between shear stress and mean velocity profile. Here the differential equations are of similar type to the laminar boundary-layer equations, so with appropriate modifications the numerical techniques developed for the latter may be carried over.

The attention of the Computer Panel had recently been brought to work done at the National Physical Laboratory on the optimization of hull form parameters based on a statistical analysis of results from model tests of trawlers. The possibility of applying similar techniques to aircraft was thought worthy of investigation, so an additional discussion group was arranged to consider this after lunch on the last day. Mr. J. G. Hayes of the National Physical Laboratory described the technique in an introductory talk based on his paper on "Optimum Hull Form Parameters" read at the symposium on "Numerical Methods Applied to Shipbuilding" held at Bergen in 1963. Mr. D. J. Doust of the National Physical Laboratory added details of the significant improvements obtained in trawler design, and a short discussion followed under the chairmanship of Mr. J. G. L. Michel (National Physical Laboratory).

No proceedings are being published, but some copies of the programme and abstracts are still available and may be obtained from Mr. P. G. Williams, Mathematics Division, National Physical Laboratory, Teddington, Middlesex, under reference $M a .8 / 35 / 02$.

P. G. Williams

\title{
BIOLOGICAL SCIENCES IN THE FUTURE UNIVERSITY OF BATH
}

$\mathrm{O}^{\mathrm{N}}$ October 14, 1965, the first and preliminary-phase building of the future University of Bath was officially opened by the Mayor of Bath. Designed by the University architcets, Robert Matthew, Johnson-Marshall and Partners, this building occupies a corner of the 197 acro site set aside by the City of Bath for the development of the new University. Constructed on the C.I.A.S.P. system, the structure was virtually completed in less than ton months, between the turning of the first sod in September 1964 to the handing over by the contractors in July 1965.

The two-storey structure forms a quadrangle, surrounding a central paved courtyard, the inner sides consisting mainly of staff offices and workrooms and the outer sides containing teaching laboratories, lecture and seminar rooms. Included in the specialist accommodation are 


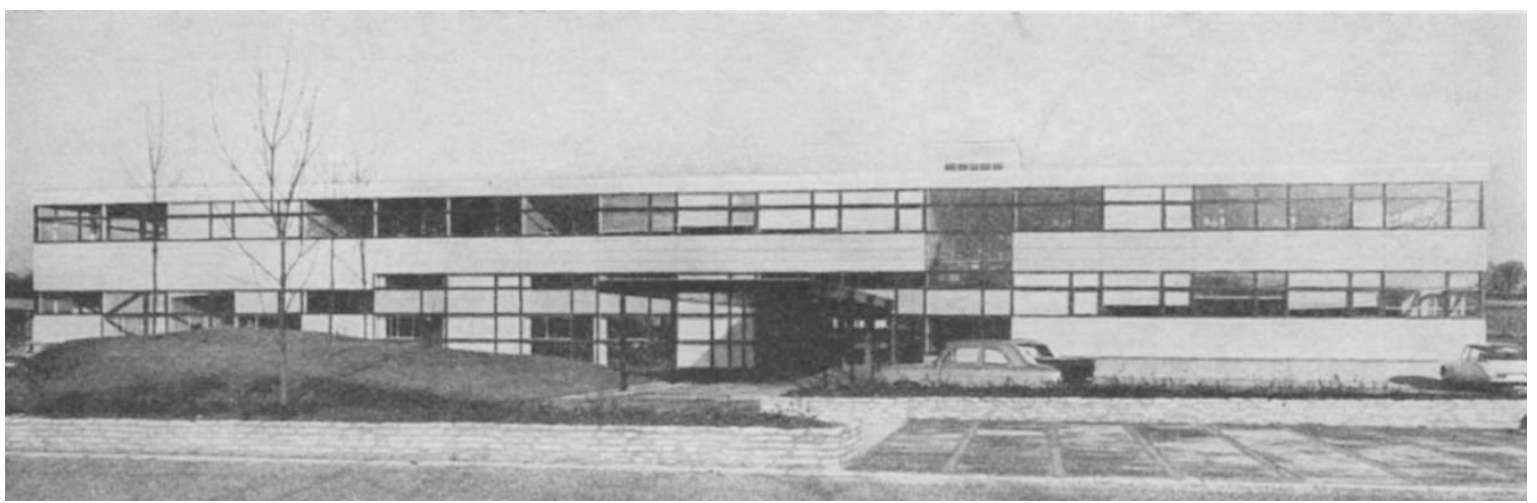

Fig. 1. The first and preiminary-phase building of the future University of Bath

laboratories for biochemistry, microbiology, crop protection, horticultural science, plant and animal physiology, electron microscopy and a variety of instrumental techniques. In addition to housing the School of Biological Sciences, about one-quarter of the total teaching space of $20,000 \mathrm{sq}$. ft. is being used by the School of Humanities and Social Sciences. The building also provides the essential ancillary accommodation, including library, refectory and staff and student common rooms. The total biological accommodation provides for an annual intake of about sixty students, giving a total for the four years of the first degree sandwich courses of about 240 , divided almost equally between the existing course in applied biology and new first degree courses in applied biochemistry and horticulture starting in the present session. The development plan for the University provides for a further instal ment of about $12,000 \mathrm{sq}$. ft. of biology accommodation in the next phase of the building programme, scheduled for completion in 1967.

The history of applied biology in the University of Bath may be traced back to 1956 when the Bristol College of Technology was designated as one of the original Colleges of Advanced Technology. At that time, in the newly-styled Bristol College of Science and Technology a four-year sandwich course in applied biology was started at the college site in Ashley Down, Bristol, under the aegis of the National Council for Technological Awards and leading to the Diploma in Technology. This course, which was designed to train biologists for employment in industry, resoarch and development, provided for three years of broadly based biological training, followed by a fourth-year specialist option in either pharmacology, microbiology, plant physiology, plant pathology or entomology. Each year of the course consisted of about equal periods in college and in industrial or research establishments. The course has since been modified in the light of experience, by an extension of the period of specialized study to two years, with the fourth year spent entirely in college, and by the combination of entomology and plant pathology in a combined course in crop protection.

The establishment of a School of Biological Sciences coincided with the opening of the new building for the autumn term. The title formally expresses the intention to preserve and extend the integration of biological education and research in those fields of biology with which the School is concerned. Both for educational reasons, and to preserve the greatest possible flexibility in students' choice of their final specialist training, it is hoped that this integration may eventually be extended by providing a common first-year course in the groundwork of biology to be followed by all new entrants to the School. For administrative convenience the teaching and research staff are divided into working groups, corresponding so far as possible with the main areas of interest within the School. Initially these groups are biochemistry, microbiology, comparative physiology, horticulture and plant physiology. The present teaching staff numbers twentytwo and there are nine research students. The head of the School and first professor of biology is Dr. L. Broadbent, at present honorary secretary of the Institute of Biology and formerly head of the Plant Pathology Division of the Glasshouse Crops Research Institute. M. W. HARdisty

\title{
POLYMERIZATION IN A GLOW DISCHARGE
}

\author{
By Dr. T. WILLIAMS and M. W. HAYES \\ British Iron and Steel Research Association, London, S.W.I
}

G LOW-DISCHARGE polymerization has been known I for many years; for example, Linder and Davies ${ }^{1}$ described the gases and solids formed by some hydrocarbon vapours in a glow discharge. In a more recent article, Brick and Knox ${ }^{2}$ have deseribed the major features and variables associated with this process. Other articles have been published describing the chemical, physical ${ }^{3}$ and electrical ${ }^{4}$ properties of glow-discharge polymers.

In glow-discharge polymerization, organic vapours at a pressure of about 1-5 torr are introduced into a chamber containing two parallel electrodes. An a.c. voltage is applied across the electrodes so as to initiate, and then sustain, a uniform glow discharge in the intervening space. High-energy ions and electrons are produced in the glow and these bombard both the electrode surfaces and the molecules in the gas phase. These interactions initiate complex chemical reactions which result in the formation of thin (up to about $5 \mu$ ) uniform and continuous coatings on the electrode surfaces.

A schematic diagram of the apparatus used in the glow discharge polymerization experiments is shown in Fig. 1. The electrodes were made of mild steel (approximately $5 \mathrm{~cm}$ by $10 \mathrm{~cm}$ ) and held in position by non-conductng supports. They were normally placed about $2 \mathrm{~cm}$ apart. The apparatus also had provisions for cooling one electrode down to a minimum temperature of $-30^{\circ} \mathrm{C}$.

The electrical equipment consisted of an oscillator and $1 \mathrm{~kW}$ audio amplifier. With frequencies of about $10 \mathrm{kc} / \mathrm{s}$ the glow was initiated at about $800 \mathrm{~V}$ and sustained at approximately $400 \mathrm{~V}$. Most of the present work was 